Original Article

\title{
Effectiveness of new sedation and rehabilitation methods for critically ill patients receiving mechanical ventilation
}

\author{
Kouji Yamashita, RPT ${ }^{1,2)^{*}}$, Akiyoshi Takami, RPT, PhD ${ }^{2)}$, SAichi WaKayama, RPT, MS ${ }^{2)}$, \\ Misato Makino, RPT, MS ${ }^{2)}$, Yoshihiro TAKeyama, MD ${ }^{3)}$ \\ 1) Department of Rehabilitation, Hakodate Municipal Hospital: 1-10-1 Minato-cho, Hakodate-shi, \\ Hokkaido 041-8680, Japan \\ 2) Hirosaki University Graduate School of Health Sciences, Japan \\ 3) Department of Critical Care Medical Center, Hakodate Municipal Hospital, Japan
}

\begin{abstract}
Purpose] The purpose of this study was to investigate the effects of new sedation management methods and cooperation between nurses and physical therapists on the duration of mechanical ventilation and hospitalization. [Subjects and Methods] Patients who had been treated at the study hospital 2 years before and after the implementation of the new methods were analyzed retrospectively and classified into a "control group" and an "intervention group", respectively. Both groups were analyzed and subsequently compared regarding the effects of the new sedation and cooperative rehabilitation. [Results] A total of 70 patients met the inclusion criteria and were divided evenly into the two groups. No significant differences were found between the groups in age, APACHE II score, or duration of stay in hospital. On the other hand, significant decreases were seen in the duration of sedation and intubation, mechanical ventilation, and stay in the emergency ward, as well as time until standing. In addition, after intervention, three patients undergoing ventilator treatment were able to be ambulated. [Conclusion] These results suggest that the new sedation and cooperative rehabilitation methods for critically ill patients were effective in the early stage of treatment and shortened the duration of stay in the ward.

Key words: Mechanical ventilation, Critically ill patients, Quality improvement
\end{abstract}

(This article was submitted Sep. 13, 2016, and was accepted Oct. 17, 2016)

\section{INTRODUCTION}

Early ambulation and exercise of critically ill adult patients have recently received increasing attention. Physical movement in the early stage is thought to shorten the duration of mechanical ventilation and the length of stay in intensive care units, prevent delirium, and lead to faster improvement in physical function. Therefore, physical movement has become a key intervention method. Early ambulation and exercise were rapidly popularized in relation to sedation management in the awakening and breathing coordination, delirium monitoring/management, and early exercise/mobility (ABCDE) bundle in $2010^{1,2)}$ and the Pain, Agitation and Delirium (PAD) guidelines in 2013 ${ }^{3)}$. The purpose of the ABCDE bundle was to reduce "iatrogenic risks" such as declined physical function resulting from oversedation and unnecessary rest, while the PAD guidelines were developed to promote a comprehensive, evidence-based, patient-centered protocol for the management of pain, agitation, and delirium. The common point shared by both sedation management approaches is that they recommended the transition from deep to light sedation, which could be beneficial in terms of early ambulation and exercise.

Historically, seriously ill patients receiving mechanical ventilation were typically managed with deep sedation, which made early ambulation and physical therapy impossible. The purpose of physical therapy for critically ill patients receiving

*Corresponding author. Kouji Yamashita (E-mail: k-yamashita@hospital.hakodate.hokkaido.jp)

(C2017 The Society of Physical Therapy Science. Published by IPEC Inc.

This is an open-access article distributed under the terms of the Creative Commons Attribution Non-Commercial No Derivatives (by-nc-nd) License $<$ http://creativecommons.org/licenses/by-nc-nd/4.0/>. 
mechanical ventilation and deep sedation at that time was to protect against or treat atelectasis, pneumonia, oxygenation failure, joint contracture, and muscle weakness. In addition, intervention was based on a chest compression technique, postural drainage, postural respiratory therapy and range of motion (ROM) exercises.

When sedation management was changed from deep to light, patients began awakening in the early stage, which made it possible for them to become ambulatory through the use of active motion; the effectiveness and safety associated with early ambulation has been previously reported ${ }^{4-12)}$. Most of the patients in those studies were in the intensive care unit (ICU); however, not many required critical care. Furthermore, in regard to early ambulation and exercise, even with sufficient analgesia and sedation management, some barriers remain among related occupations, such as a lack of communication, cooperation, adequate workforce, and knowledge of and interest in early ambulation ${ }^{9-13)}$.

Our hospital previously administered deep sedation to critically ill parents. Rehabilitation for critically ill patients was primarily conducted by physical therapists, and respiratory management involved respiratory physical therapy, which was introduced for the prevention and/or treatment of joint contracture and respiratory complications. Although ambulation was sometimes possible, many cases were seen in which physical therapists treated their patients individually; however, because of a lack of cooperation and communication with nurses, patients could not normally achieve early ambulation or recover physical function.

In 2012, the sedation method for patients in the emergency department of our hospital was changed with the introduction of a sedation vacation ${ }^{14)}$ (sedation vacation is daily interruption sedation). In addition, our hospital launched a new project known as "quality improvement and rehabilitation activities" to address the problem of a lack of cooperation and communication with nurses.

The aim of this study was to examine the effectiveness of our newly implemented methods for the sedation and rehabilitation of mechanically ventilated patients in the emergency department and their future implications.

\section{SUBJECTS AND METHODS}

A flow diagram of the present study is shown in Fig. 1. The participants were patients who had been diagnosed by a rehabilitation specialist after admission and were undergoing rehabilitation in the emergency department, had required mechanical ventilation, and had reacquired walking ability at discharge. Patients who had died in the hospital, had had a poor neurological prognosis, had been mechanically ventilated $\leq 48 \mathrm{~h}$, had been reintubated, had been $<18$ years of age during hospitalization, had had ambulation difficulties for medical reasons, or had required long-term social hospitalization were excluded. Patients who had not acquired walking ability at discharge were excluded, in order to confirm the ambulation.

This was a retrospective study. All patient data were used only for the purposes of this study, and adequate measures were taken to ensure the privacy of such data. Patients who had been treated at our hospital 2 years before (April 1, 2010 to March 31, 2012) and after (April 1, 2012 to March 31, 2014) the implementation of the new sedation and rehabilitation methods were identified and subsequently classified into a "control group" and an "intervention group", respectively. This study was approved by the ethics committee of Hakodate Municipal Hospital (JIN2016-4).

The intervention technique for rehabilitation. Following the doctor's instructions, patients started engaging in passive ROM exercises for the extremities and respiratory physical therapy while lay and seated upright to prevent respiratory complications. Next, active exercise was started in accordance with the awakening of the patients. When patients were able to be ambulatory from their bed, we started having them sit at the edge of the bed, transfer from sitting to standing, and then walk. Targeted patients also had to meet the following parameters before the initiation of physical therapy: heart rate $\leq 120$ beats per minute (bpm), diastolic blood pressure (DBP) $\leq 120 \mathrm{mmHg}$, systolic blood pressure (SBP) $\leq 200 \mathrm{mmHg}$, and no angina, palpitation, or shortness of breath (SOB) at rest. The intervention would stop when the patients had dyspnea (moderate), dizziness, vomiting, heart rate $\geq 140 \mathrm{bpm}$, premature ventricular contractions or tachyarrhythmia and bradycardia, $\geq 40$ $\mathrm{mmHg}$ increase in SBP, or $\geq 20 \mathrm{mmHg}$ increase in DBP. The intervention was interrupted and resumed after recovery when patients had $\geq 30 \%$ increase in heart rate, a heart rate $\geq 120 \mathrm{bpm}$, or mild SOB.

However, limitations in SBP/DBP and percutaneous oxygen saturation were also set for individual patients by the doctors, and all doctors' orders were prioritized. In addition, when an adverse event occurred, it was reported to the doctors as soon as possible and their instructions were followed. Furthermore, the following had to be shown in order to attempt ambulation: permission from the doctor: response to verbal stimuli and simple commands; adequate pain control; and a stable respiratory condition and hemodynamics. Ambulation attempts were stopped for patients who refused or showed distress, were considered likely to remove their catheter or drip, or had an instable respiratory condition or hemodynamics.

The research items were as follows: age; acute physiology and chronic health evaluation score (based on the Acute Physiology and Chronic Health Evaluation [APACHE II] classification); period from admission to the hospital until the start of rehabilitation; duration of sedation and analgesia; duration of intubation and mechanical ventilation; time until able to get out of bed, stand, and walk; duration of stay in the emergency ward; duration of stay in the hospital; number of intubated and mechanically ventilated patients achieving early ambulation; and adverse events that required additional treatment (none were noted). APACHE II scores were worse 24 hours after admission to our emergency and critical care center because the patients' physical conditions tended to stabilize after admission and the severity of their illness could not be reflected in the scores. In addition, the ward for critically ill patients at our hospital is known as the High Care Unit (HCU), and duration of 
Table 1. Change of strategy, sedative and rehabilitation

\begin{tabular}{|c|c|c|}
\hline & $\begin{array}{l}\text { Control } \\
(1, \text { April,2010-31,March,2012) }\end{array}$ & $\begin{array}{l}\text { Intervention } \\
\text { (1,April,2012-31,March,2014) }\end{array}$ \\
\hline \multicolumn{3}{|c|}{ Department of emergency (by the doctor) } \\
\hline Practice of sedation & Continuous intravenous infusion & Sedation vacation \\
\hline Sedative & Propofol and midazolam & Propofol and dexmedetomidine \\
\hline \multicolumn{3}{|c|}{ A quality of improvement of rehabilitation (by the physical therapist and nursing staff) } \\
\hline Activity level (admission order) & Doctor's order & As tolerated (in wheel chair) \\
\hline Mobilization (staffing) & Only physical therapist & Collaboration (nurse and physical therapist) \\
\hline Practice of rehabilitation & Week day & $\begin{array}{l}\text { Across the } 7 \text { days week established to rehabilitation schedule } \\
\text { (for the purposes rehabilitation) }\end{array}$ \\
\hline
\end{tabular}

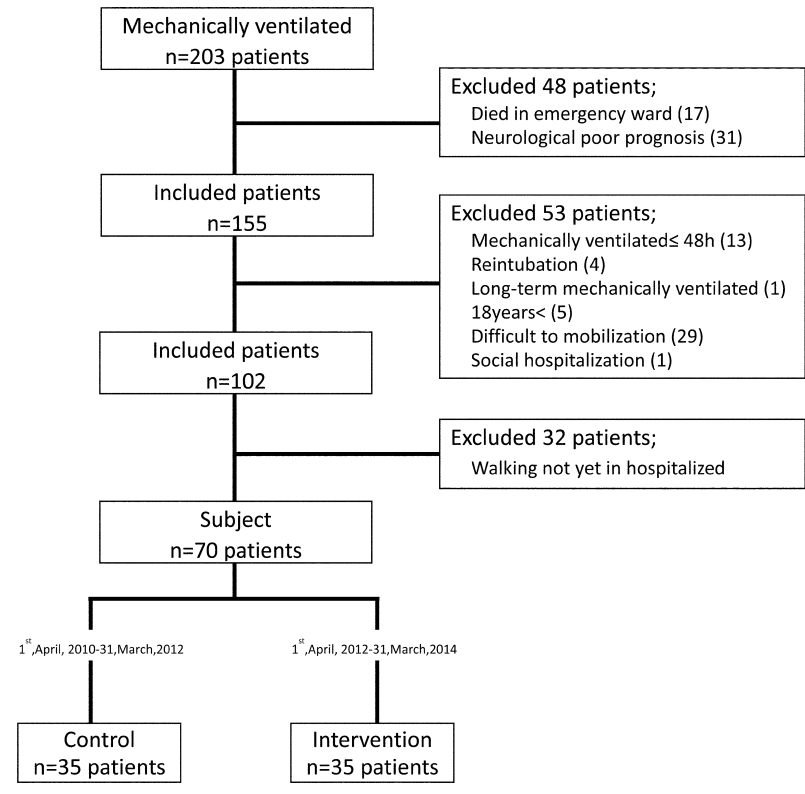

Fig. 1. Process for the included studies
Table 2. Patient's Characteristics of the study population

\begin{tabular}{lcc}
\hline & $\begin{array}{c}\text { Control } \\
(\mathrm{n}=35)\end{array}$ & $\begin{array}{c}\text { Intervention } \\
(\mathrm{n}=35)\end{array}$ \\
\hline Cardiopulmonary arrest/ & 13 & 13 \\
Post cardiac-arrest syndrome & 3 & 3 \\
$\quad$ Endogenous & 10 & 10 \\
Cardiogenic & 6 & 7 \\
Trauma & & 1 \\
$\quad$ Head injury & 4 & 4 \\
Thoracic injury & & 1 \\
Abdominal injury & 2 & \\
Inhalation burn & & 1 \\
Others & 5 & 5 \\
Acute poisoning & 2 & 1 \\
Drowning & 4 & 5 \\
Hypoxic encephalopathy & 5 & 4 \\
Others & 1 & 1 \\
Corrosive esophagitis & 1 & \\
Thyroid crisis & 1 & 1 \\
Severe pneumonia & 1 & \\
Pulmonary edema & & 1 \\
Acute respiratory distress syndrome & & 1 \\
Sepsis & 1 & \\
\hline
\end{tabular}

stay in hospital was the duration of stay for patients requiring critical care in each ward.

A change in sedation management was made from continuous intravenous infusion of sedatives to sedation vacation as follows (Table 1): the sedatives were changed from benzodiazepines to dexmedetomidine, and a sedation vacation in which sedation is stopped once per day when sustainable sedation is possible was introduced as the sedation method.

Project content for "quality improvement and rehabilitation activities". The standardized admission orders were that the default activity level was changed from "bed" to "wheelchair" when patients under the regular care of nurses had no limitations. After confirmation, nurses shared the patient information with physical therapists. In addition, a physical therapy plan was developed in coordination with the nurses, and an intervention time was arranged in advance. Physical therapy regimens were changed from weekdays to 7 days a week.

All collected data were statistically analyzed using the Student t-test and the Mann-Whitney U test. SPSS was used for all statistical analyses (version $22 \mathrm{~J}$ for Windows; IBM SPSS Japan Inc., Tokyo, Japan). P values $<0.05$ were considered statistically significant.

\section{RESULTS}

A total of 70 patients were finally included in this study (35 in the control group and 35 in the intervention group). The critically ill patients included those with post-cardiac arrest syndrome, trauma, and acute poisoning (Table 2). Significant 
Table 3. Outcomes according to study group

\begin{tabular}{lcc}
\hline & Control $(\mathrm{n}=35)$ & Intervention $(\mathrm{n}=35)$ \\
\hline Age (years) & $55.4( \pm 14.84)$ & $56.85( \pm 15.04)$ \\
APACHE II score & $23(17-28)$ & $28(19-33)$ \\
Time from admission (days) & & \\
To rehabilitation's request & $4(2-6.5)$ & $3(2-5)$ \\
To rehabilitation's order & $4(3-7)$ & $4(2-5.5)$ \\
Duration of sedation, analgesia, intubation, and ventilation (days) & $5(4-7)^{*}$ \\
Duration of sedation & $7(5-8)$ & $4(3-6)$ \\
Duration of analgesia & $5(4-6.5)$ & $5(4-7)^{*}$ \\
Duration of intubation & $7(6-9)$ & $5(5-7)^{*}$ \\
Duration of mechanical ventilation & $7(6-9)$ & $7(6-11)^{*}$ \\
Time from admission to milestones achieves (days) & & $9(7-13)^{*}$ \\
Out of bed & $10(8-15)$ & $11(7-16)$ \\
Standing & $11(8.5-18.5)$ & $9(7-12)^{*}$ \\
Walking & $13(9.5-20.5)$ & $29(16-37)$ \\
Length of stay in emergency a ward (days) & $12(9-14)$ & $35(27.5-45.5)$ \\
Length of stay in hospital (days) & & \\
\hline
\end{tabular}

Values are shown as mean $( \pm \mathrm{SD})$ or median (IQR).

$* \mathrm{p}<0.05$ compared with control group.

differences were observed between groups in the duration of sedation and analgesia, duration of intubation and mechanical ventilation, time until able to get out of bed, stand, and walk, and duration of stay in the emergency ward $(p<0.05)$. In addition, after intervention, three patients undergoing respirator treatment could be ambulated. No adverse events requiring additional treatment by a physical therapist were noted (Table 3 ).

\section{DISCUSSION}

As a result of the "quality improvement and rehabilitation activities" project for emergency department patients at our hospital, the duration of sedation and analgesia, duration of intubation and mechanical ventilation, time until being able to get out of bed, stand, and walk, and duration of stay in the emergency ward were shortened.

The previous aim of sedation management for critically ill patients was to facilitate ventilation and prevent both psychological and physiological problems, including pain, anxiety, agitation and delirium, resulting from inadequate treatment ${ }^{3)}$. On the other hand, because of bed rest resulting from deep sedation, barriers such as muscle atrophy, atelectasis, pneumonia, dependence on mechanical ventilation, thromboembolism, decubitus ulcers, and delirium have been reported ${ }^{8,15-19)}$.

Kollef $^{20)}$ and Kress ${ }^{21)}$ reported that changing the method and duration of sedation from continuous bolus administration to daily interruption of sedation (DIS) would result in significant differences in mechanical ventilation management by reducing the amount and duration of sedation and protecting against respiratory complications ${ }^{19}$. However, a noted complication of DIS is a significant increase in the blood concentration of catecholamine, as well as increases in heart rate and $\mathrm{BP}^{22)}$. Therefore, much care is needed for ambulation and exercise of patients with cardiovascular disease.

Benzodiazepines such as midazolam and lorazepam have been shown to be associated with a longer duration of mechanical ventilation than non-benzodiazepines such as propofol and dexmedetomidine ${ }^{23-26)}$. Furthermore, significant reductions in the duration of mechanical ventilation have been observed in patients receiving light sedation management, which also allows early ambulation and exercise ${ }^{3,8}$. Needham ${ }^{18)}$ introduced "quality improvement project for early ambulation" in order to promote changes in sedation practice and a rearrangement of the staff; this led to a reduced duration of stay in the hospital or ICU. Furthermore, comprehensive intervention management makes early ambulation possible and leads to a variety of positive effects.

Our findings also showed significant reductions in the duration of sedation, analgesia, and mechanical ventilation. Therefore, we believe that reducing the duration of sedation and mechanical ventilation facilitates early awakening and significantly shortens the time until achieving ambulation. On the other hand, ambulation was primarily achieved after weaning from mechanical ventilation. Ambulation typically refers to movements for which the patient is assisted in bed, such as positioning, passive and active limb exercises, and continuous rotation therapy involving the use of specialized beds ${ }^{27)}$. Therefore, in this study, we focused on the ambulation of critically ill patients receiving mechanical ventilation.

In addition, ambulation is difficult to achieve by only shortening the duration of sedation, and some adverse events have been reported for seriously ill patients attempting ambulation; therefore, patient care and safety must be kept in mind when 
considering the appropriateness of ambulation for each patient. For interventions involving rehabilitation and ambulation, it is necessary to assess cardiopulmonary status, to take great care in managing tubes (such as feeding and chest) and catheters (such as central venous, peripheral intravenous, and arterial), and to predict falls based on muscle strength and awakening, as well as orthostatic disorders associated with sitting and standing. An adequate rehabilitation staff is also needed to provide sufficient care for seriously ill patients, and rehabilitation activities may need to be increased in order to achieve significant improvements in physical function ${ }^{10,18}$. Therefore, in order to quicken the start of rehabilitation and reduce delays in achieving ambulation, it is necessary for institutions to maintain an adequate workforce and properly manage issues such as staff holidays.

To address these issues, the "quality improvement and rehabilitation activities" project implemented at our hospital called for the following: adequate staffing; risk management of tubes (such as feeding and chest) and catheters (such as central venous, peripheral intravenous, and arterial) by nurses; fall prevention strategies by physical therapists; discussions of rehabilitation scheduling (such as starting time, regimen, and outcomes); and proper planning of staff holidays. The comprehensive implementation of this project led to significant improvements in the quality of rehabilitation at our hospital. Furthermore, changing the attitudes of physical therapists and nurses toward ambulation led to significant improvements in regard to intubated patients becoming ambulatory.

However, not all of the patients in our hospital succeeded in achieving early ambulation and exercise; some still required long-term sedation and had an unstable physical condition, while others still had difficulty standing ${ }^{28,29)}$ and a poor neurological prognosis (such as cervical cord injury or post-cardiac arrest syndrome). For patients with reduced physical function, active intervention is needed ${ }^{30)}$; previous evidence-based respiratory physical therapy should be maintained, and efforts must be made to prevent further complications.

The purpose of previous rehabilitation methods, which were also considered respiratory management methods, was to protect seriously ill patients from respiratory failure during bed rest. In the future, the need for increased active intervention for physical disorders and a revised purpose for rehabilitation is also expected.

This study did have some limitations. First, it was a retrospective study conducted in a single facility. Second, no association was found between a reduction in the duration of sedation and the use of an artificial respirator. Third, we could not validate the standard criteria for being released from the emergency department or the hospital.

The revised sedation method and "quality improvement and rehabilitation activities" project introduced for emergency department patients in our hospital led to reductions in the duration of sedation and analgesia, duration of intubation and mechanical ventilation, time until being able to get out of bed, stand, and walk, and duration of stay in the emergency ward. Therefore, these updated methods are expected to generate many positive effects for patients receiving mechanical ventilation in the future.

\section{REFERENCES}

1) Vasilevskis EE, Ely EW, Speroff T, et al.: Reducing iatrogenic risks: ICU-acquired delirium and weakness-crossing the quality chasm. Chest, 2010, 138: 1224-1233. [Medline] [CrossRef]

2) Pandharipande P, Banerjee A, McGrane S, et al.: Liberation and animation for ventilated ICU patients: the ABCDE bundle for the back-end of critical care. Crit Care, 2010, 14: 157. [Medline] [CrossRef]

3) Barr J, Fraser GL, Puntillo K, et al. American College of Critical Care Medicine: Clinical practice guidelines for the management of pain, agitation, and delirium in adult patients in the intensive care unit. Crit Care Med, 2013, 41: 263-306. [Medline] [CrossRef]

4) Zafiropoulos B, Alison JA, McCarren B: Physiological responses to the early mobilisation of the intubated, ventilated abdominal surgery patient. Aust J Physiother, 2004, 50: 95-100. [Medline] [CrossRef]

5) Bailey P, Thomsen GE, Spuhler VJ, et al.: Early activity is feasible and safe in respiratory failure patients. Crit Care Med, 2007, 35: 139-145. [Medline] [CrossRef]

6) Needham DM: Mobilizing patients in the intensive care unit: improving neuromuscular weakness and physical function. JAMA, 2008, 300: 1685-1690. [Medline] [CrossRef]

7) Morris PE, Goad A, Thompson C, et al.: Early intensive care unit mobility therapy in the treatment of acute respiratory failure. Crit Care Med, 2008, 36: 2238-2243. [Medline] [CrossRef]

8) Schweickert WD, Pohlman MC, Pohlman AS, et al.: Early physical and occupational therapy in mechanically ventilated, critically ill patients: a randomised controlled trial. Lancet, 2009, 373: 1874-1882. [Medline] [CrossRef]

9) Hopkins RO, Spuhler VJ, Thomsen GE: Transforming ICU culture to facilitate early mobility. Crit Care Clin, 2007, 23: 81-96. [Medline] [CrossRef]

10) Zanni JM, Korupolu R, Fan E, et al.: Rehabilitation therapy and outcomes in acute respiratory failure: an observational pilot project. J Crit Care, 2010, 25: 254-262. [Medline] [CrossRef]

11) Bourdin G, Barbier J, Burle JF, et al.: The feasibility of early physical activity in intensive care unit patients: a prospective observational one-center study. Respir Care, 2010, 55: 400-407. [Medline]

12) Winkelman C: Investigating activity in hospitalized patients with chronic obstructive pulmonary disease: a pilot study. Heart Lung, 2010, 39: 319-330. [Medline] [CrossRef]

13) Leditschke IA, Green M, Irvine J, et al.: What are the barriers to mobilizing intensive care patients? Cardiopulm Phys Ther J, 2012, 23: 26-29. [Medline]

14) Egerod I: Is taking a sedation vacation all it's cracked up to be? Crit Care Med, 2008, 36: 2205-2206. [Medline] [CrossRef] 
15) Dock W: The evil sequelae of complete bed rest. JAMA, 1944, 125: 1083-1085. [CrossRef]

16) Kong R, Payen D: Controlling sedation rather than sedation controlling you. Clin Intensive Care, 1994, 5: 5-7. [Medline]

17) De Jonghe B, Bastuji-Garin S, Fangio P, et al.: Sedation algorithm in critically ill patients without acute brain injury. Crit Care Med, 2005, 33: 120-127. [Medline] [CrossRef]

18) Needham DM, Korupolu R, Zanni JM, et al.: Early physical medicine and rehabilitation for patients with acute respiratory failure: a quality improvement project. Arch Phys Med Rehabil, 2010, 91: 536-542. [Medline] [CrossRef]

19) Schweickert WD, Gehlbach BK, Pohlman AS, et al.: Daily interruption of sedative infusions and complications of critical illness in mechanically ventilated patients. Crit Care Med, 2004, 32: 1272-1276. [Medline] [CrossRef]

20) Kollef MH, Levy NT, Ahrens TS, et al.: The use of continuous i.v. sedation is associated with prolongation of mechanical ventilation. Chest, 1998, 114: 541-548. [Medline] [CrossRef]

21) Kress JP, Pohlman AS, O'Connor MF, et al.: Daily interruption of sedative infusions in critically ill patients undergoing mechanical ventilation. N Engl J Med, 2000, 342: 1471-1477. [Medline] [CrossRef]

22) Riker RR, Shehabi Y, Bokesch PM, et al. SEDCOM (Safety and Efficacy of Dexmedetomidine Compared With Midazolam) Study Group: Dexmedetomidine vs midazolam for sedation of critically ill patients: a randomized trial. JAMA, 2009, 301: 489-499. [Medline] [CrossRef]

23) Kress JP, Vinayak AG, Levitt J, et al.: Daily sedative interruption in mechanically ventilated patients at risk for coronary artery disease. Crit Care Med, 2007, 35: 365-371. [Medline] [CrossRef]

24) Weinbroum AA, Halpern P, Rudick V, et al.: Midazolam versus propofol for long-term sedation in the ICU: a randomized prospective comparison. Intensive Care Med, 1997, 23: 1258-1263. [Medline] [CrossRef]

25) Searle NR, Côté S, Taillefer J, et al.: Propofol or midazolam for sedation and early extubation following cardiac surgery. Can J Anaesth, 1997, 44: 629-635. [Medline] [CrossRef]

26) Hall RI, Sandham D, Cardinal P, et al. Study Investigators: Propofol vs. midazolam for ICU sedation : a Canadian multicenter randomized trial. Chest, 2001, 119: 1151-1159. [Medline] [CrossRef]

27) Clini E, Ambrosino N: Early physiotherapy in the respiratory intensive care unit. Respir Med, 2005, 99: 1096-1104. [Medline] [CrossRef]

28) Göcze I, Strenge F, Zeman F, et al.: The effects of the semirecumbent position on hemodynamic status in patients on invasive mechanical ventilation: prospective randomized multivariable analysis. Crit Care, 2013, 17: R80. [Medline] [CrossRef]

29) Daihua $Y$, Wei C, Xude S, et al.: The effect of body position changes on stroke volume variation in 66 mechanically ventilated patients with sepsis. J Crit Care, 2012, 27: 416.e7-416.e12. [Medline] [CrossRef]

30) Stockley RC, Hughes J, Morrison J, et al.: An investigation of the use of passive movements in intensive care by UK physiotherapists. Physiotherapy, 2010, 96 : 228-233. [Medline] [CrossRef] 